\title{
Implantable cardioverter defibrillator for the prevention of sudden cardiac death: Systematic review and pooled analysis
}

\author{
Aref Albakri* \\ St-Marien hospital Bonn Venusberg, Department of Internal Medicine, Bonn, Germany
}

\begin{abstract}
Implantable cardioverter defibrillator (ICD) is an innovative biomedical device designed to detect and terminate malignant ventricular arrhythmias (VAs) with convincing evidence of substantial life-saving properties. Its prophylactic use for sudden cardiac death (SCD) in patients resuscitated from cardiac arrest or at risk for malignant VAs has revolutionized the face of clinical care for many cardiac diseases with a shift from antiarrhythmic drugs. Progressive improvements in ICD device has expanded the prophylactic use of ICD to include pre-emptive therapy in a large population of patients with significantly depressed left ventricular systolic function. This expansion increased the incidence of inappropriate shocks potentially affecting treatment efficacy. Moreover, inadequate attention paid to the patient's psychosocial concerns and cost-effectiveness of therapy has affected treatment outcomes as well as quality of life. The knowledge of these complications and challenges is critical for appropriate selection of patients who will benefit from the therapy as well as improve treatment outcomes. The purpose of this literature review and pooled analysis is to summarize the current knowledge base of clinical indications, treatment outcomes, psychosocial concerns and healthcare costs for ICD patients and to identify gaps in ICD literature that would be appropriate targets for future research.
\end{abstract}

\begin{abstract}
Abbreviations: AAD: Anti-Arrhythmic Drugs; ACC: American College of Cardiology; AHA; American Heart Association; ARVD: Arrhythmogenic Right Ventricular Dysplasiap; ATP: Anti-Tachycardia Pacing; AV: Atrioventricular; AVID: Antiarrhythmic Versus Implantable Defibrillators; CAD: Coronary Artery Disease; DCM: Dilated Cardiomyopathy; FDA: Food and Drug Administration; GSC: German Society of Cardiology; HCM: Hypertrophic Cardiomyopathy; HF: Heart Failure; ICD: Implantable Cardioverter-Defibrillator; LQT: Long QT Syndrome; LV: Left Ventricular; LVNC: LV Non-Compaction; MI: Myocardial Infarction; QoL: Quality of Life; RA: Right Atrial; RV: Right Ventricle; SCD: Sudden Cardiac Death; SVT: Sustained Ventricular Tachycardia; VF: Ventricular Fibrillation; VT: Ventricular Tachycardia.
\end{abstract}

\section{Introduction}

Sudden cardiac death (SCD) resulting from sustained ventricular arrhythmias (VAs) in the setting of structural heart disease has emerged as a substantial public health problem affecting approximately 70,000 to 100,000 individuals annually in the United Kingdom [1]. The current standard treatment for VA is antiarrhythmic drug (AAD) therapy usually amiodarone or sotalol but $\sim 25 \%$ of the patients withdraw from treatment because of adverse side effects. However, over the past four decades, implantable cardioverter-defibrillator (ICD) has grown into a safe and efficacious alternative prophylaxis for malignant VAs. It was the product of a decade-long research and pre-clinical testing culminating in the first successful implantation in a human being in 1980 [2]. Since then, several landmark clinical trials have associated ICD therapy with significant reduction in arrhythmia-related mortality in selected heart failure (HF) patient populations.

Despite demonstrated life-saving benefits, the initial uptake of ICD therapy was slow because of the rejection by nearly all members of the medical community [3]. Four decades later, ICD therapy continues to encounter specific challenges, in particularly patient selection and psychosocial concerns [4]. ICD therapy may also result into clinical complications such as infection, inappropriate ICD shocks, proarrhythmias, device malfunction, adverse negative media publicity, and procedural complications, which may affect treatment outcomes and quality of life (QoL) [5]. This review re-appraises the benefits and challenges of ICD therapy, and developments to improve physicians and patients understanding, acceptance and appreciation of the ICD therapy.

\section{Innovation and history}

The history and development of ICD therapy began in the 1950s following the recognition that VAs is the major pathophysiological mechanism leading to death in large proportions of patients with cardiac diseases. Later in the 1960s, the advent of several treatment strategies for VAs such as electronic monitoring, cardiopulmonary resuscitation and synchronized cardioversion shifted medical attention to the treatment of arrhythmias among hospitalized patients in coronary care units [6-8]. By contrast, the major public health problem of SCD outside of the coronary care unit continued to receive little attention yet it bordered on an epidemic [9]. In the 1980s, SCD was the initial

*Correspondence to: Aref Albakri, St-Marien hospital Bonn Venusberg, Department of Internal Medicine, Bonn, Germany, E-mail: arefalbakri@yahoo.com

Key words: implantable cardioverter-defibrillators, prevention of sudden cardiac death, sustained ventricular tachycardia

Received: January 25, 2019; Accepted: February 11, 2019; Published: February 13, 2019 
presentation of cardiac disease in $15 \%$ of HF patients [10] and over $50 \%$ of SCD occurred outside the coronary care units creating an urgent need to develop a reliable clinical intervention for the prevention of SCD outside of the coronary care units [11]. As early as the 1960s, Michel Mirowski was among a few clinicians to recognize the scope of the public health problem of SCD and subsequently pioneered the innovation of the original ICD device and its initial implantation in a human being [10].

The original ICD was a biomedical device designed for implantation in HF patients previously resuscitated from cardiac arrest. The driving design concept was to deliver an internal electric shock to a patient's heart immediately after VAs to restore normal sinus rhythm, and consequently, reinstate life [9]. Although ICD prototype research began in the 1960s based on dog models, the initial reception of the prototype data was sceptical, with suggestions that the researchers trained the dogs to behave in certain ways using Pavlovian conditioning [4]. Additionally, the concept that ICD could identify and terminate potentially lethal life-threatening arrhythmias received rejection by nearly all members of the medical community. In particular, a leading authority on defibrillation published a scathing editorial in the Circulation postulating the development of ICD was impossible and unethical to test in a human being because of the requirement to induce ventricular fibrillation (VF) [13].

Beyond this initial rejection, the medical community gradually recognized that ICD promised to address a specific form of cardiac death - the epidemic of SCD - and improve mortality rates of the large population at risk [4]. Consequently, the first successful human implantation was in 1980 at John Hopkins Hospital and with it came a paradigm shift for clinical prevention of SCD from AAD therapy and ablative strategies to ICD therapy. The publication of antiarrhythmic versus implantable defibrillators (AVID) multicentre trial for the secondary prevention of SCD in 1997 [13] inspired a series of tests for ICD in broader and lower-risk primary prevention patient populations. These series of tests transformed the ICD from a restricted last line therapy for patients resuscitated from cardiac arrest to include a broader pre-emptive (primary prevention) therapy for population at high risk for life-threatening arrhythmias [14]. About three decades later, the annual implantation of ICDs increased by more than 20-fold [15].

\section{The ICD device}

\section{The device}

The initial ICD devices were large $\left(8 \times 11.5 \mathrm{~cm}, 170 \mathrm{~cm}^{3}\right)$ and heavy $(280 \mathrm{~g})$ and not programmable. They used epicardial patch electrodes and required thoracotomy for implantation of the epicardial lead system [16]. With progressive improvements, the current devices are relatively small (weighing as little as $90 \mathrm{~g}$ and measuring $<1 \mathrm{~cm}$ thick), and in the majority of cases, implanted subcutaneously and connected to an endocardial lead system [16]. At its basic, an ICD contains a battery, a capacitor to store and deliver charges, a microprocessor and integrated circuits for electrogram sensing, data capture, storage and control of therapy delivery, a header to canned endocardial leads used for sensing, pacing and defibrillation - all of these encased in a titanium can [17]. All together, these components form the pulse generator, and collaborate to perform the essential functions of ICD including sensing, detecting and classification of arrhythmias, delivering therapy (ventricular defibrillation or anti-tachycardia pacing [ATP]), monitoring posttherapy rhythm, and storage of episodes [17].

The design of the early devices was to recognise and terminate VF by delivering a high-energy shock and thus were unable to detect unstable ventricular tachycardia (VT) [17]. The development of 2nd generation ICD facilitated bradycardia-pacing capabilities, were minimally programmable, had limited telemetry function for testing battery strength and thus simply noted the number of delivered shocks. They required an external monitoring device for telemetry function. In the early 1990s, the third generation ICD introduced ATP and lowenergy shocks for terminating VTs and extensive programmability and telemetry function [18]. Remote monitoring in modern ICD has improved patient security and reduced inconvenience. If a patient experiences cardiac symptoms, suspects ICD shock or in need of routine device check-up, remote monitoring allows the patient to connect to a monitoring system at home and transmit ICD-recorded activities to the physician. The physician team reviews and determines the need for medical changes and/or office visits as well as reassures the patient about device and cardiac functioning [4].

\section{Device selection}

Careful selection of appropriate ICD device is critical to improve treatment outcomes. The cardiac electrophysiologist should careful select pulse generator and leads that produce the greatest impact on procedural time and complexity, follow-up, patient outcomes and cost. At present, available choices for pulse generators include single, dual or bi-ventricular devices; unipolar versus bipolar pacing or sensing configuration; the presence and type of sensor for rate response; and advance features such as automatic capture verification, arterial therapies, and battery size and capacity. The available choices for leads include diameter, polarity, type of insulation material, and active or passive fixation mechanisms $[19,20]$. Other important factors for consideration in device selection include capabilities of programmer for the pacemakers, local availability of technical support, and capabilities of remote monitoring. Subsequent to implantation of the pacing system, the cardiac electrophysiologist has to choose appropriate pacing mode, pulse width and amplitude, sensitivity and refractory period, and the delay between LV and RV pacing for bi-ventricular pacing [20].

\section{How device works}

The ICD system comprises of a pulse generator implanted below the left or right clavicle, and depending on the type of ICD device, could have one to three electrodes placed transvenously into different chambers of the heart [21]. For a single chamber ICD, the insertion of the single electrode is in the right ventricle (RV). However, in a majority of patients, the implanted ICD is usually dual chamber where insertion of the two electrodes is in the right atrial (RA) and RV. In selected HF patients indicated for a dual therapy of ICD and cardiac resynchronization therapy (CRT)-ICD, they receive an additional LV electrode implanted through the coronary sinus in a posterolateral epicardial vein [22]. In addition to sensing and pacing capabilities that is same to that found in a conventional bradycardia pacemaker, the ICD has the ability to detect potentially harmful VAs and to terminate them by ATP or shock discharges [21].

The defibrillation lead has a coil at the level of the RV, and optionally a second one in the superior vena cava, known as proximal coil. For shock treatment, the ICD delivers electrical energy ( 1 to 40 joules) between the ventricular defibrillation coil, the device can, and the proximal defibrillation coil. The programming for the detection window for VT and VF, and the sequence for treatment (ATP, lowenergy shock and high-energy shock) is specific to the individual patient receiving the ICD [21]. The ICD has software algorithms, which enable the device to discriminate between atrial and ventricular arrhythmias. However, inappropriate shocks may still occur due to various causes 
such as supraventricular tachycardia, signal misinterpretation, and electromagnetic interference (Table 1) [22]. The current generation of ICDs are able to store information from various diagnostic features including intracardial ECG registrations during arrhythmias and transmit the data through remote monitoring technology. Moreover, the device can generate audible alarms in case of device malfunction, low battery capacity and/or lead failure to alert the patient [21].

\section{Indications for ICD therapy}

The selection of patients to implant ICD is a complex clinical decision involving careful discussion among healthcare providers and the patient. However, the ultimate decision usually rests with the cardiac electrophysiologist, who is also responsible for appropriate programming and long-term follow-up of the device. For other treating physicians, it is important to understand which patients to refer to a cardiologist or electrophysiologist for consideration for ICD implantation [3]. There are cases when ICD therapy is inappropriate such as when the cause of arrhythmia is transient or reversible. In such cases, the first line treatment should be curative. Such cases include catheter ablation in patients with Wolff-Parkinson-White syndrome, surgical ablation in patients with an old myocardial infarct (MI) and preserved LV function, well-circumscribed aneurysm and inducible monomorphic VT. Patients with acute ischaemia may initially require revascularization or appropriate drugs. Drugs such as beta-blockers are first line treatment in a majority of patients with symptomatic congenital long QT (LQT) syndrome. Patients with a short life expectancy $(<6$ months) are usually inappropriate candidates for ICD implantation while psychiatric patients present a challenge in acceptance of ICD therapy and in follow-up in the outpatient clinic $[23,24]$.

\section{Treatment aims}

Consensus guidelines on ICD therapy from leading cardiology societies - the ESC [23], the American College of Cardiology/ American Heart Association (ACC/AHA) [24] and the German Society of Cardiology [GSC] [25] - recommend two therapeutic aims of the ICD therapy - the prevention of SCD (a) due to SVT; and (b) due to indirectly life threatening monomorphic VT.

Prevention of sustained ventricular arrhythmias: The first therapeutic aim is the protection against SCD, which in a large majority of cases, is a consequence of SVT, described as hemodynamic symptoms (syncope, pre-syncope and chest pain) or VT lasting $>30$ seconds. Asystole (defined as a cardiac arrest rhythm with no discernible electrical activity on the EKG monitor or flatline EKG) as a secondary event may occur after a long-lasting VF. However, primary asystole as a cause of SCD is rare in patients with severely impaired LV function. The ICD detects and terminate the arrhythmia by ATP or electric shock delivery and pacing in cases of bradycardia [23].
Prevention of indirect monomorphic ventricular arrhythmias: The second therapeutic aim of ICD is the prevention of SCD due to indirectly life threatening monomorphic VT, in which case, ICD therapy may automatically terminate arrhythmia by ATP, and if needed, by electric shock. Termination by ATP is potentially painless and may occur without the patient awareness of the arrhythmia, and thus, has a favourable effect on QoL [23]. While an electric shock triggers body movement because the electric field between the electrodes is not limited to the heart, ATP does not cause body movement, and without loss of consciousness, contributes to fitness for driving [24].

\section{Ventricular tachyarrhythmias}

The two general therapeutic strategies of ICD as a prophylaxis for SCD in the setting of structural heart diseases are primary and secondary prevention. Primary prevention describes the protection against the initial occurrence of a life-threatening arrhythmia such as SVT, VF or cardiac arrest. On the other hand, secondary prevention describes protection against the recurrence of potentially fatal arrhythmia or cardiac arrest among patients who have had prior clinical events of that type of arrhythmia [26]. Ventricular tachyarrhythmias originating in the ventricles namely monomorphic and polymorphic VT and VF) are more life threatening than any other tachyarrhythmias [27].

Monomorphic ventricular tachycardia: Monomorphic VT characterized by pulse rate $>100 \mathrm{bpm}$ and QRS complexes with a uniform morphology is an uncommon arrhythmia that is more prevalent in men. It may appear as unsustained VT within a range of three consecutive beats to paroxysmal VT lasting $\leq 30$ seconds. When sustained ( $>30$ seconds) it requires conversion because it may lead to hemodynamic deterioration [28]. The most common cause of monomorphic VT is coronary artery disease (CAD) but may also occur in the setting of cardiomyopathy, rheumatic heart disease or in the absence of any demonstrable evidence of structural heart disease, and occasionally occur in association with a variety of other cardiac conditions. Complaints of rapid heart action is a common sign in patients experiencing monomorphic VT. Other common signs include chest pain, dyspnoea, weakness and neurological symptoms such as fainting. A typical clinical symptom of monomorphic VT is a rapid heart rate. Other common symptoms include signs of varying systolic blood pressure, large A-waves in the neck veins, changing intensity of the first heart sound, and systolic murmurs that identify atrioventricular dissociation [28].

Electrocardiogram (ECG) abnormalities associated with monomorphic VT include regular or slightly irregular tachycardia with QRS complexes greater than the normal width appearing as the right or the left bundle branch block. The QRS complexes have a constant (monomorphic) form. Monomorphic VT is can be distinguished from

Table 1. Causes of appropriate and inappropriate ICD shocks (Modified from Gehi, et al. [22])

\begin{tabular}{|c|l|}
\hline Nature of ICD Shock & Causes of ICD Shock \\
\hline \multirow{3}{*}{ Appropriate shocks } & Ventricular fibrillation \\
\cline { 2 - 2 } & Monomorphic ventricular tachycardia \\
\cline { 2 - 2 } & Polymorphic ventricular tachycardia \\
\hline \multirow{2}{*}{ Unnecessary shocks } & Torsades de pointes \\
\hline \multirow{2}{*}{ Inappropriate shocks } & Haemodynamically tolerated non sustained VT \\
\hline & $\begin{array}{l}\text { Supraventricular tachycardia (atrial fibrillation, atrial flutter, atrial tachycardia) and sinus tachycardia } \\
\text { failure, insulation brake) }\end{array}$ \\
\hline & Electromagnetic interference \\
\hline Phantom shocks & Patient perceives an ICD shock with describable sensations, even though the memory of the ICD indicates that no shock. \\
\hline
\end{tabular}


atrial or supraventricular tachycardia with aberrant conduction using clinical history, physical examination and a careful review of ECG [28]. In the diagnosis of VT, the width of QRS complexes greater than 0.14 seconds or presence of atrioventricular (AV) dissociation, concordance or fusion beats. Late potentials are frequent during sinus rhythm in signal-averaged ECG of patients with SVT. Severe hemodynamic distress during SVT produces many of the observed symptoms as well as hypotension and depressed ventricular function. Programmed stimulation of the ventricles often terminates VT [29]. Unsustained VT does not require specific treatment but ICD should be considered in CAD patients with depressed LV systolic function. Finally, prognosis of patients with recurrent VT is favourable in those with unsustained VT in the absence of structural heart disease but unfavourable as ventricular function deteriorates due to myocardial infarction (MI), cardiomyopathy or other cardiac diseases [29].

Polymorphic ventricular tachycardia: Polymorphic VT is an uncommon arrhythmia characterized by a pulse rate $>100 \mathrm{bpm}$ with continuously varying QRS complex morphology in any recorded ECG lead [29]. Most patients have organic heart disease and take AAD, many of which may prolong the QT intervals during sinus rhythm. Torsades de pointes is a specific form of polymorphic VT characterized by rapid, irregular QRS complexes, which appear to be twisting around the ECG baseline. It develops in patients with long QT (LQT) interval, LQT syndrome or normal QT intervals during sinus rhythm [28]. Most patients with polymorphic VT have CAD or cardiomyopathy but few may have no underlying structural heart disease. Bradycardia induced by AV block or sick sinus syndrome can produce polymorphic VT. Syncope is the most dramatic symptom and the leading reason for presentation at the clinic. A typical ECG feature is the changing form of QRS complexes. Morphology and axis changing from beat-tobeat or within a group of beats with prolonged and varying duration. Bidirectional tachycardia is a special variety of polymorphic VT with a rapid and regular rhythm, and the alternating morphology of abnormally wide QRS [28]. The characteristic ECG feature of the LQT syndrome is abnormally prolonged corrected QT (QTc) interval during sinus rhythm. Exercise shortens the QT interval less than observed in normal patients with drug-induced torsades de pointes of the LQT syndrome. Torsades de pointed occurs more often in patients with depressed LV systolic function [30].

Programmed stimulation in the electrophysiology lab rarely induces torsades de pointes or another SVT in patients with LQT intervals, even those with a history of spontaneous episodes of polymorphic VT [28]. The arrhythmia can however be produced with an ECG form that closely resembles spontaneous episodes in patients with a history of the arrhythmia but without electrolyte disturbances, AAD therapy or ischaemia induced polymorphic VT may progress to monomorphic VT or VF. Usually, acute treatment of torsades de pointes and polymorphic VT is rarely necessary. However, when the arrhythmia persists and acutely endangers the patients, cardioversion produces sinus rhythm, at least temporarily [28]. Temporary pacing is the most reliable intervention to suppress recurrent episodes until the application of a more definitive treatment. Drugs such as isoproterenol and magnesium are also effective. If the cause of the problem is proarrhythmia, discontinuation of the causative drug is an effective option. When the arrhythmias persist despite these interventions, ICD should be indicated. While beta-blockers and/or left cardiac sympathetic denervation are preferred interventions for preventing torsades de pointes, syncope and VF in patients with inherited LQT syndrome, ICD should be considered when arrhythmias persist [31].
Ventricular fibrillation: Ventricular fibrillation (VF) results from chaotic ventricular activity shown by bizarre and uncoordinated ECG traces in which cardiac arrest occurs within seconds and death within minutes if not corrected immediately. VF is the most frequent cause of cardiac arrest and accounts for at least $80 \%$ of SCD outside of the hospital [32]. The incidence of VF-associated SCD is very low in the young but increases rapidly over the age of 45 years. Cardiac arrest is more common in patients who are awake, active, cigarette smokers, obese, less educated or have survived prior cardiac arrest. Often, patients suffering from cardiac arrest $>30$ years of age have CAD, usually involving three vessels, previous MI and depressed LV systolic function. Almost 50\% of survivors of out-of-hospital cardiac arrest have MI. However, VF develops in relatively few patients with MI receiving medical care [28]. The incidence of VF is the highest after the onset of MI and is prevalent in patients with anterior or large infarctions, congestive heart failure, AF, AV block or bundle branch block. Opening coronary obstruction responsible for the MI using thrombolysis or angioplasty reduces the probability of VF during hospitalization. Approximately 25\% of DCM patients die suddenly and cardiac arrest is responsible for a majority of deaths in HCM patients [28]. Half of congestive HF is sudden and are mostly due to aortic stenosis, congenital anomalies of coronary arteries, congenital complete AV block, Ebstein disease, Eisenmenger syndrome, and Tetralogy of Fallot are the principal congenital lesions producing cardiac arrest and VF [32].

A continuous undulating ECG pattern characterizes VF. Warning arrhythmias predicting VF are ventricular premature beats that are multiform, coupled, or occur more frequently than five-per-minute or in the early part of the preceding T-wave. VT during MI more frequently changes into VF when persisting with greater than 100 beats or faster than $180 \mathrm{bpm}$, polymorphic or initiated by an R-on-T beat. In a majority of patients with VF, they show abnormal signal-averaged ECG and heart rate variability [32]. About $50 \%$ of VF patients with CAD have positive exercise tests. Spontaneous conversion occurs in many episodes of VT including VF. In the electrophysiology lab, SVT and infrequently VF can be induced in most patients resuscitated from cardiac arrest but less often in patients with stable SVT and more often in patients with organic heart disease compared to patients with idiopathic VF [28]. Inducing VF is rare in patients with DCM resuscitated from cardiac arrest. There is need to convert VF quickly if the patient is to recover. Conversion should be through precordial thump version, and if a pulse does not return immediately, performance of chest compression and artificial respiration is necessary [28]. Early electrical defibrillation and ECG monitoring are critical. Recurrence of arrhythmia requires intravenous lidocaine, procainamide or amiodarone followed by electrophysiology evaluation. If patient history suggest VF was the cause of cardiac arrest in the absence of other reversible causes such as acute ischaemia or pro-arrhythmic drug, ICD should be implanted. $\mathrm{AAD}$ therapy is no longer considered adequate therapy. About half of patients resuscitated from cardiac arrest die in hospital and one-third of those discharged die within three years. The ICD therapy dramatically reduces mortality of discharged survivors [26].

\section{Cardiac diseases causing ventricular tachyarrhythmias}

Current consensus guidelines [23-25] recommend the use for ICD therapy for secondary and primary prevention of SCD in patients with the following cardiac diseases - CAD, dilated cardiomyopathy (DCM), hypertrophic cardiomyopathy (HCM), arrhythmogenic right ventricular dysplasia (ARVD), valvular heart disease, Long QT syndromes and primary electrical disorders - that are the leading causes of VT and/or VF. 
Coronary artery disease: Coronary artery disease $(\mathrm{CAD})$ describes an impedance or obstruction of one or more arteries supplying blood to the myocardium, often due to atherosclerosis, characterized by episodes of reversible myocardial demand/supply mismatch. If untreated, CAD could potentially result in arrhythmias and HF [33]. CAD patients experiencing cardiac arrest in the setting of VF greater than 48 hours after myocardial infarction (MI) are at risk of recurrent cardiac arrest and are candidates for ICD therapy. However, CAD patients with prolonged episodes of sustained monomorphic VT or VF accompanied by marked increases in cardiac troponin and creatine phosphokinase levels should prompt evaluation for ischemia. If there is evidence of ischaemia preceding the onset of VF without MI, the most appropriate therapy should be coronary revascularization. If revascularization is not possible and there is evidence of significantly depressed LVEF, ICD should be the primary therapy after resuscitation from VF or as a prophylactic for the initial VF $[14,34]$.

Non-ischaemic dilated cardiomyopathy: Non-ischaemic dilated cardiomyopathy (DCM) is a progressive and usually irreversible myocardial disorder characterized by left or biventricular dilation and global contractile dysfunction not explained by chronic abnormal loading conditions such as hypertension and valvular disorders or CAD [35]. Patients with non-ischaemic DCM and prior episodes of VF or sustained VT are at risk for recurrent cardiac arrest. Empirical antiarrhythmic therapy or medical therapy guided by electrophysiology testing has not shown improved survival in these patients. Thus, ICD is the preferred treatment for patients with non-ischaemic DCM resuscitated from cardiac arrest due to VF or VT as well as for the primary prevention of life-threatening ventricular arrhythmias [34].

Hypertrophic cardiomyopathy: Hypertrophic cardiomyopathy (HCM) is a myocardial disorder marked by unexplained LV thickening associated with non-dilated ventricular chambers not explained by other known cardiac or systemic disorders [36]. It is the most common cause of SCD in individuals younger than 40 years especially during exertion because exercise increases the risk of life-threatening VAs [25]. HCM patients with a history of cardiac arrest indicates a risk for future VT/VF and ICD should be the preferred therapy [37]. In some asymptomatic HCM patients, SCD may be the first manifestation of the disease and these patients may benefit from ICD therapy. In addition, HCM patients without sustained VT or syncope, ICD implantation may be considered where there is a family history of SCD at a young age [14].

Arrhythmogenic right ventricular dysplasia: Arrhythmogenic right ventricular dysplasia (ARVD) is a hereditary condition characterized by fibro-fatty infiltration of the RV and sometimes the LV. It manifests with sustained monomorphic VT with left bundle morphology. In these patients, ICD therapy has shown a very high proportion of appropriate use for life threatening arrhythmias and low rate of arrhythmic death for secondary prevention for SCD [14]. While ICD recommendations include primary prevention of SCD in ARVD patients, well-defined predictive markers of SCD in ARVD patients are lacking. There is a need for large prospective studies based on large registries with rigorous inclusion criteria for ARVD patients with ICD for primary prevention to give insights into risk stratification techniques. Nevertheless, clinical factors that can help identify patients at risk for life-threatening arrhythmias include induced VT during electrophysiological testing, non-sustained VT on non-invasive monitoring, the male gender, severe RV dilation and extensive RV involvement [14]. Patients with ARVD-associated genotypes and high risk of SCD should be considered for primary prevention of SCD [38].
Genetic arrhythmia syndromes: Patients with genetic syndromes such as LQT, short QT, Brugada, idiopathic VF and catecholaminergic polymorphic are at risk of sustained VT/VF. These electrical disorders manifest in the absence of structural heart diseases and increase the risk of SCD. In these patients, prior cardiac arrest or syncope is a predictor of the risk for recurrent VF or VT. With clear evidence of the benefits of pharmacotherapy on survival lacking, ICD is the preferred therapy for patients with prior arrhythmic events. For patients with a strong family history of early mortality, prophylactic ICD therapy may be considered. For LQT patients with strong family history of SCD, or who are non-compliant or intolerant to optimal pharmacotherapy, they may benefit from ICD for the primary prevention of SCD [14,34]. Risk stratification for SCD in patients with Brugada syndrome is important since ICD therapy is the only prophylactic intervention to prevent SCD $[39,40]$.

LV non-compaction: LV non-compaction (LVNC) is a rare form of congenital cardiomyopathy characterized by excessive prominent trabeculae and deep inter-trabecular recesses in the LV due to the arrest of normal embryogenesis [41]. Major complications of the LVNC include VAs and SCD. There are no clinically useful markers for risk stratification for life threatening VAs in LVNC patients. While clinical trials or registry data on LVNC are lacking, observational studies suggest that ICD implantation is a reasonable strategy for the primary prevention of SCD in LVNC patients [14].

\section{Treatment effect of ICD on mortality}

The primary treatment aim of ICD therapy is prophylaxis for SCD. Thus, many clinical trials on treatment efficacy of ICD therapy usually evaluate its effect on mortality rate, an in most cases, compared to conventional antiarrhythmic therapy or placebo. Mortality rate evaluated can be death from any cause or deaths due to cardiac or arrhythmic causes. To determine effect sizes of ICD therapy on mortality, we performed a pooled analysis of large-scale prospective multicentre trials comparing ICD therapy with conventional antiarrhythmic therapy (AAD) therapy or placebo.

Prospective multicentre trials: Twelve large prospective trials have since been published evaluating treatment efficacy of ICD therapy on the prevention of SCD in selected patient populations at risk of SCD: AVID [13], CASH [42], CIDS [43], MADIT I [44], MUSTT [45], MADIT II [46], DEFINITE [47], SCD-HeFT [48], CAT [49], AMIOVIRT [50], CABG-Patch [51] and DINAMIT [52]. The summary of the details of each trial - name of the trial, the number of enrolled patients, mean age, gender presentation (percentage of male patients), inclusion criteria, mean follow-up period and main findings - are provided in Table 2.

Secondary preventive trials: Three trials evaluated the efficacy of ICD therapy on secondary prevention of SCD in comparison to AAD therapy. The AVID trial [13] compared treatment efficacy of ICD and conventional AAD therapy in patients resuscitated from near-fatal ventricular fibrillation (VF), sustained VT (SVT) with syncope or SVT with LVEF $\leq 40 \%$. ICD therapy reduced mortality after one, two and three years by $39 \%, 27 \%$, and $31 \%$ respectively. The CASH trial [42] evaluated prophylactic use of ICD for SCD in patients resuscitated from cardiac arrest. Compared to AAD therapy, ICD achieved 23\% reduction in all-cause mortality but the reduction was non-significant. The CIDS trial [43] compared treatment effect of ICD therapy and medical therapy with amiodarone on mortality in patients who have survived VF or SVT, and found ICD therapy had superior protection effect against SCD (relative risk [RR] 19.7\%; 95\% CI: $27.7 \%$ to $40 \%$ ) but the reduction was not statistically significant. 
Table 2. Features of Multicenter Clinical Trials Included for Pooled Analysis

\begin{tabular}{|c|c|c|c|c|c|c|}
\hline Trial & $\begin{array}{l}\text { No of Patients } \\
\text { (ICD/AAD) }\end{array}$ & $\begin{array}{l}\text { Male } \\
(\%)\end{array}$ & Mean Age & Inclusion Criteria & $\begin{array}{l}\text { Mean Follow- } \\
\text { up (Months) }\end{array}$ & Main Findings \\
\hline AVID [13] & $507 / 509$ & 78 & $65(11)$ & $\mathrm{VF}, \mathrm{SVT}, \mathrm{LVEF} \leq 0.40$ & 18.2 & $\begin{array}{l}\text { Reduced mortality ( } 95 \% \text { CI) ICD were } 39 \pm 20 \%, 27 \pm 21 \% \text {, and } \\
\qquad 31 \pm 21 \% \text { at } 1,2 \text {, and } 3 \text { years }(\mathrm{p}<0.02)\end{array}$ \\
\hline CASH [42] & $99 / 189$ & 79 & $58(11)$ & $\begin{array}{l}\text { Resuscitated from CA, } \\
\text { secondary Sustained VA }\end{array}$ & 57.3 & $23 \%$ non-significant reduction of all-cause mortality \\
\hline CIDS [43] & $328 / 321$ & 85 & $63(9)$ & $\mathrm{VF}, \mathrm{CA}, \mathrm{SVT}$ no $\mathrm{AMI} \leq 72 \mathrm{hrs}$ & 36.0 & $\begin{array}{l}\text { Non-significant reduction in the risk of death (RR } 19.7 \% ; 95 \% \\
\text { CI: } 27.7 \% \text { to } 40 \% ; p=0.142)\end{array}$ \\
\hline MADIT I [44] & $95 / 101$ & 92 & $62(9)$ & $\begin{array}{l}\text { Inducible, sustained, non- } \\
\text { suppressible VT LVEF }<35 \%\end{array}$ & 27.0 & $\begin{array}{l}\text { Reduction in overall mortality HR: } 0.46 ; 95 \% \text { CI: } 0.26 \text { to } 0.82 \text {; } \\
\qquad \mathrm{P}=0.009) .\end{array}$ \\
\hline MUSTT [45] & $161 / 190$ & 90 & 67 & $\begin{array}{c}\mathrm{CAD}, \mathrm{LVEF} \leq 40 \% \text {, and } \\
\text { asymptomatic non-sustained } \mathrm{VT}\end{array}$ & 39.0 & Mortality reduction RR $0.40 ; 95 \%$ CI $(0.27-0.59) \mathrm{p}<0.001$ \\
\hline MADIT II [46] & $742 / 490$ & 84 & $64(10)$ & Reduced LVEF $\leq 30 \%$ after MI & 20.0 & Reduced mortality HR $0.69 ; 95 \%$ CI: 0.51 to $0.93 ; \mathrm{P}=0.016$ ) \\
\hline DEFINITE [47] & $229 / 229$ & 73 & 58 & $\begin{array}{l}\text { Non-ischaemic DCM/LVEF } \\
<36 \% \text {, premature ventricular } \\
\text { complexes or non-sustained VT }\end{array}$ & 29.0 & Reduced mortality HR $0.65 ; 95 \%$ CI 0.40 to $1.06 ; \mathrm{P}=0.08$ \\
\hline SCD-HeFT [48] & $829 / 845$ & 77 & 60 & $\begin{array}{l}\text { NYHA II/III, chronic, stable } \\
\text { CHF due to ischemic or non- } \\
\text { ischemic causes, LEVF }<35 \%\end{array}$ & 45.4 & Reduced mortality HR $0.77 ; 97.5 \%$ CI 0.62 to $0.96 ; \mathrm{P}=0.00$ \\
\hline CAT [49] & $50 / 54$ & 86 & 52 & $\begin{array}{c}\mathrm{DCM} \leq 9 \text { months, } \mathrm{LVEF} \leq 30 \% \\
\text { and NYHA II/III }\end{array}$ & 22.7 & $\begin{array}{l}\text { Cumulative survival } 92 \%, 86 \% \text {, and } 73 \% \text { in ICD group versus } \\
93 \%, 80 \% \text {, and } 68 \% \text { in the control group after } 2,4 \text {, and } 6 \text { years }\end{array}$ \\
\hline AMIOVIRT [50] & $51 / 52$ & 67 & 58 & $\begin{array}{l}\text { NIDCM, LVEF } \leq 30 \% \text {; NYHA } \\
\text { I-III, Asymptomatic NSVT }\end{array}$ & 24.0 & $\begin{array}{c}\text { ACD/AAD - Survival rates at one year }(90 \% \text { vs. } 96 \%) \text { and } 3 \\
\text { years }(88 \% \text { vs. } 87 \%)\end{array}$ \\
\hline CABG-Patch [51] & $446 / 454$ & 87 & $64(9)$ & $\begin{array}{l}\text { CABG patients }<80 \\
\text { years; LVEF }<36 \% \text {; ECG } \\
\text { abnormalities }\end{array}$ & 32.0 & $\begin{array}{l}7.9 \% \text { absolute mortality reduction }(\mathrm{p}=0.003) \text { in patients with } \\
\text { LVSD receiving optimal medical therapy }\end{array}$ \\
\hline DINAMIT [52] & $311 / 342$ & 74 & $61(11)$ & $\begin{array}{l}\text { MI 6-40 days before } \\
\text { randomization, } \mathrm{LVEF} \leq 35 \%\end{array}$ & 30.0 & $\begin{array}{l}\text { Decrease risk of arrhythmic death (HR: } 0.33 ; 95 \% \text { CI: } 0.15 \text { to } \\
0.71 \text { ) but an increase in non-arrhythmic death (HR: } 1.70 ; 95 \% \\
\text { CI: } 1.00 \text { to } 2.80 \text { ). }\end{array}$ \\
\hline
\end{tabular}

AAD: Antiarrhythmic Drugs; AMI: Acute Myocardial Infarction; AMIOVIRT: Amiodarone Versus Implantable Cardioverter-Defibrillator Randomized Trial; AVID: Antiarrhythmic Versus Implantable Defibrillators; CA: Cardiac Arrest; CABG: Coronary Artery Bypass Graft; CASH: Cardiac Arrest Study Hamburg; CAT: Cardiomyopathy Trial; CIDS: Canadian implantable defibrillator study; DEFINITE: Defibrillators in Non-Ischemic Cardiomyopathy Treatment Evaluation; DINAMIT: Defibrillation in Acute Myocardial Infarction Trial; ICD: Implantable Cardioverter Defibrillator; RCT: Randomized Controlled Trial; MADIT: Multicenter Automatic Defibrillator Implantation; MI: Myocardial Infarction; MUSTT: Multicenter Unsustained Tachycardia Trial Investigators; SCD-HeFT: Sudden Cardiac Death in Heart Failure Trial; SVT: Sustained Ventricular Tachycardia; VA: Ventricular Arrhythmia

Primary preventive trials: The MADIT trial evaluated the effect of ICD on survival in patients with ischaemic heart diseases who are at risk of arrhythmic death [44]. Compared to conventional therapy using AAD, ICD had a lower mortality rate (16\% vs. $39 \%)$ and achieved a $54 \%$ reduction in overall mortality ( $95 \%$ CI: $26 \%$ to $82 \%$ ). In CAD patients with LVEF $\leq 40 \%$, the MUSTT trial [45] reported ICD therapy compared to AAD reduced mortality by $60 \%$ (RR: $0.40 ; 95 \%$ CI $0.27-0.59 ; \mathrm{p}<0.001)$. In patients with myocardial infarction (MI) and depressed LVEF (<30\%), the MADIT II trial [46] reported ICD therapy provided superior protection against all-cause mortality (HR 0.69; $95 \%$ CI: 0.51 to $0.93 ; \mathrm{p}=0.016$ ) while the DINAMIT trial [52] found reduction in arrhythmic death (HR: 0.33 ; $95 \%$ CI: 0.15 to 0.71 ). The DEFINITE [47] and AMIOVIRT [50] trials evaluated treatment effect of ICD and AAD on non-ischaemic DCM patients with depressed LVEF $(<36 \%$ and $<30 \%)$. The trials found ICD led to a non-significant $35 \%$ decrease in death from all causes (HR 0.65; 95\% CI 0.40 to 1.06) [47] and higher survival rates at one and three years $(90 \%$ and $88 \%$ vs. $96 \%$ and 87\%) [50]. The SCD-HeFT trial [48] compared ICD and conventional AAD therapy on patients with CHF and reduced LEVF $(<35 \%)$ and associated ICD with a significant reduction in all-cause mortality (HR $0.77 ; 97.5 \%$ CI 0.62 to $0.96 ; p=0.00$ ). In patients with idiopathic DCM $\leq$ 9 months to hospitalization and LVEF $\leq 30 \%$, the CAT trial [49] found ICD treatment achieved higher cumulative survival rates of $92 \%, 86 \%$ and $73 \%$ compared to AAD 93\%,80\% and $68 \%$ after 2, 4 and 6 years respectively. The CABG-Patch trial [51] investigated patients who had undergone CABG surgery with $\mathrm{LVEF}<36 \%$ and showed ICD led to $7.9 \%$ absolute reduction in mortality.

\section{Pooled analysis of treatment efficacy of ICD on mortality}

\section{Methods}

Calculation of pooled treatment effect of ICD preventing SCD utilized raw data - the number of patients who died in both the ICD and non-ICD treatment arms - extracted only from published data from the 12 trials $[13,42-52]$. The relative risk (RR) with $95 \%$ confidence interval (CI) using fixed and random effect size models were calculated for individual trials and the overall analysis. Statistical heterogeneity across the 12 trials was calculated using the chi-square and $\mathrm{I}^{2}$ statistics. When pooled results showed significant heterogeneity $\left(I^{2} \geq 50 \%\right)$ the random effect models was used and in the absence of heterogeneity or very low heterogeneity $\left(\mathrm{I}^{2}<50 \%\right)$, the fixed effect models was used. Statistical significance was obtained when $\mathrm{p}$-value was $>0.05$.

\section{Results}

The twelve trials had a combined population of 7,624 patients randomized into ICD $(n=3,848)$ and non-ICD (AAD therapy or placebo: $n=3,776)$. In the ICD group, a greater majority were male patients $(81 \%)$. The mean age of the ICD treatment arm was 61 years, range 52 to 67 years. The mean follow-up period was 31.7 months, range 18.2 to 57.3 months. There were 702 deaths from any cause and 208 deaths due to cardiac causes in the ICD group compared to 906 allcause deaths and 303 cardiac deaths in the non-ICD group. When all deaths from any cause was pooled using the random effects model in all the 12 trials, there was a $24 \%$ relative reduction in the ICD group (RR: 0.76; 95\% CI: 0.701-0.830; $\mathrm{p}=0.000$ ) (Figure 1). When all deaths due 
to cardiac causes were pooled using the random effect model in seven trials $[33-35,37,40-42]$, there was $39 \%$ relative reduction in the ICD group (RR: 0.61; 95\% CI: 0.411-0.903; $\mathrm{p}=0.014$ ) (Figure 2). When data was pooled using the random effect model for three RCTs $[12,32,33]$ for secondary prevention of $\mathrm{SCD}$, the ICD group had a relative reduction of $24 \%$ in mortality (RR: 0.76 ; $95 \%$ CI: $0.650-0.884 ; \mathrm{p}=0.000$ ) (Figure 3). In primary prevention of $S C D$ in, the ICD group also had a relative reduction in mortality in nine studies [34-42] of $27 \%$ (RR: 0.73 ; $95 \% \mathrm{CI}$ : 0.586-0.917; $\mathrm{p}=0.007$ ) (Figure 4).

\section{Discussion}

This pooled analysis of twelve large-scale prospective multicentre randomized trials clearly demonstrates that the implantation of ICD for primary or secondary prevention of SCD in selected patients at risk of life-threatening VT or VF significantly reduces both all-cause

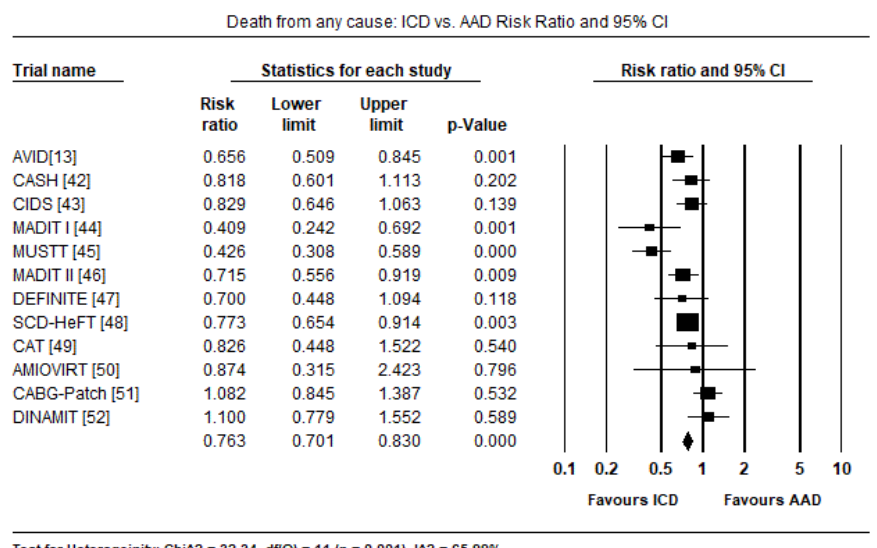

Figure 1. Death from all Causes - ICD vs. AAD Risk Ratio and $95 \% \mathrm{CI}$

Death from Cardiac Causes of SCD: ICD vs. AAD Risk Ratio and $95 \% \mathrm{Cl}$

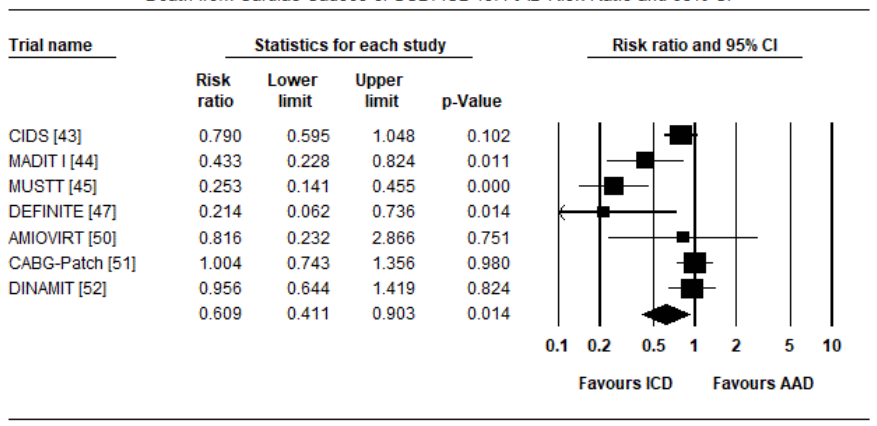

Figure 2. Death from Cardiac Causes - ICD vs. AAD Risk Ratio and 95\% CI

Secondary Prevention of SCD: ICD vs. AAD Risk Ratio and $95 \% \mathrm{Cl}$

\begin{tabular}{|c|c|c|c|c|c|}
\hline \multirow[t]{2}{*}{ Trial name } & \multicolumn{4}{|c|}{ Statistics for each study } & Risk ratio and $95 \% \mathrm{Cl}$ \\
\hline & $\begin{array}{l}\text { Risk } \\
\text { ratio }\end{array}$ & $\begin{array}{l}\text { Lower } \\
\text { limit }\end{array}$ & $\begin{array}{l}\text { Upper } \\
\text { limit }\end{array}$ & p-Value & \\
\hline AVID[13] & 0.656 & 0.509 & 0.845 & 0.001 & 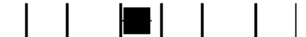 \\
\hline CASH [42] & 0.818 & 0.601 & 1.113 & 0.202 & \\
\hline \multirow[t]{4}{*}{ CIDS [43] } & 0.829 & 0.646 & 1.063 & 0.139 & \\
\hline & 0.758 & 0.650 & 0.884 & 0.000 & \\
\hline & & & & & $\begin{array}{lllll}0.1 & 0.2 & 0.5 & 1 & 2\end{array}$ \\
\hline & & & & & Favours AAD \\
\hline
\end{tabular}

Figure 3. Secondary Prevention of SCD - ICD vs. AAD Risk Ratio and 95\% CI
Primary Prevention of SCD: ICD vs. AAD Risk Ratio and $95 \% \mathrm{Cl}$

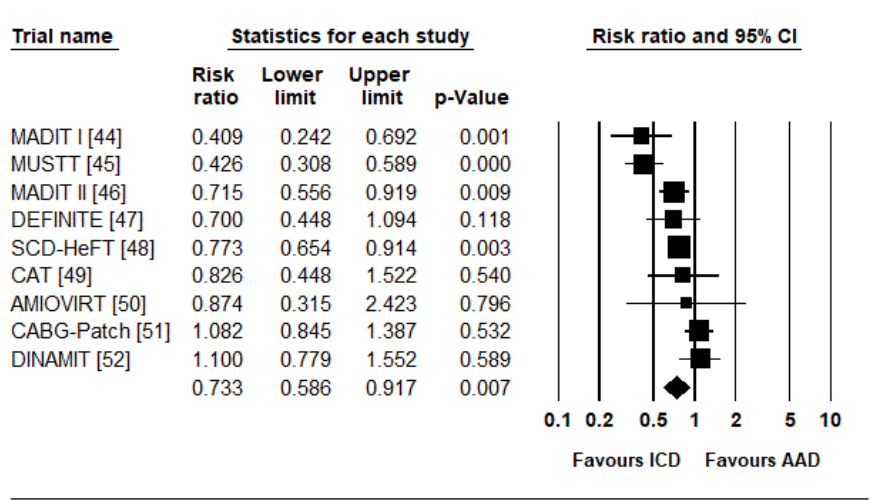

Test for Heterogeinity: Chi^ $2=30.35, \mathrm{df}(\mathrm{Q})=8(\mathrm{p}=0.000), 1 \wedge 2=73.64 \%$

Figure 4. Primary Prevention of SCD - ICD vs. AAD Risk Ratio and 95\% CI

and cardiac deaths at intermediate-term follow-up compared to the conventional AAD therapy. The present finding also demonstrates ICD therapy for primary prevention reduces all-cause deaths in patients with LV systolic dysfunction irrespective of aetiology and QRS duration. While these findings may provide estimates of reduction in mortality in selected HF patient populations, it is difficult to determine mortality rates in individuals with $\mathrm{HF}$ in the general population who require ICD therapy and for whom comorbidities differ from those in trial populations from which prediction models have been developed [24].

While the present findings demonstrate that ICD therapy significantly reduces mortality due to SVT or VF, analysis did not address confounding factors in individual trials that may potentially improve survival in the selected patient populations. Prior CABG surgery has been shown to reduce the risk of death by $25 \%$ and the risk of SCD by $46 \%$ independent of LVEF and the severity of HF symptoms [53]. When compared to patients with LV systolic dysfunction who have not undergone $\mathrm{CABG}$, the predicted rates of death from any cause and from SCD was $8.2 \%$ and $2.4 \%$ respectively, which are comparable to those reported in the CABG-Patch trial [51]. This finding suggest that CABG surgery could have affected the effect of ICD on mortality in the CABG-Patch trial [51]. In addition, the combined effect of ICD shock therapy, medication (such as angiotensin-converting-enzyme inhibitor and beta-blocker) and revascularization on LVEF over time is also difficult to quantify.

An important issue emerging from the present analysis is variations in the criteria used to include patients in the twelve trials. For the three trials evaluating secondary prevention of SCD $[13,42,43]$, the basis of patient selection was resuscitation from prior cardiac arrest. By contrast, the trials evaluating the primary prevention of SCD [44-52] irrespective of the various underlying cardiac disease such as MI, non-ischaemic DCM and congestive HF, the common selection criterion was significantly depressed LV systolic function. However, the range of LVEF used in the trials varied significantly from $\leq 40 \%[12,35], \leq 36 \%[37,41],<35 \%[34,38,42]$ to $\leq 30 \%[36,40]$, To accommodate these variations, the ACC/AHA/ESC 2006 guidelines for management of patients with VAs and prevention of SCD recommends LVEF $\leq 40 \%$ to justify ICD implantation for primary prevention of SCD [21]. The findings suggest the lack of a gold standard for LVEF values for selecting patients for the primary prevention of SCD. In addition, the various clinical methods of LVEF determination also lack precision and their accuracy vary based on laboratories and institutions [24]. 
Finally, although the present findings show the prophylactic use of ICD therapy for SCD reduced the overall mortality among enrolled patients, there is an inherent risk that those included in clinical trials may have been selected for the likeliness they will comply with followup and concomitant medical therapies. Whether unselected patient population will have the same extent of therapeutic benefits from prophylactic ICD therapy remains unknown. Moreover, ICD devices may not be appropriate for all the patients who met the inclusion criteria in the individual studies. Both patient and clinician should also consider comorbidities having competing effects on mortality. The current ESC recommendations for ICD therapy for primary prevention of SCD apply only to patients receiving optimal medical therapy with reasonable expectation of survival and favourable functional status within one year. Therefore, additional clinical trials are warranted to develop widely accepted guidelines for selecting appropriate high-risk patients who will benefit from prophylactic ICD implantation.

\section{Post-implantation monitoring}

The ICD therapy does not prevent malignant arrhythmias from occurring but detects and terminates them. Post-implantation ICD management is critical component of the therapy and essential for therapeutic success. The ESC guidelines emphasize on the importance of periodic and meticulous follow-up to ensure safety and optimal device performance as well as to monitor the clinical status of the patient [14]. The goals of monitoring ICD patients should include monitoring device functionality; optimizing device performance for treatment efficacy and device longevity; anticipating and replacing system components and tracking devices; timely intervention for clinical problems; patient tracking, education and support; and maintaining ICD system records [14,23]. Each patient should have individualized follow-up according to clinical status and performed by a physician fully trained in ICD followup. Although a six-month interval for device follow-up is ideal for many patients, a more frequent evaluation may be required based on device features and patient's clinical status. At present, device automaticity and remote monitoring have greatly facilitated follow-up [14]

\section{Concerns for ICD therapy}

Despite convincing evidence in clinical trials for treatment efficacy of ICD in mortality reduction, the impact of inappropriate shocks, patient's psychosocial concerns and high costs on ICD acceptance and use remain less certain. However, these three factors may potentially affect the efficacy of ICD therapy.

Inappropriate ICD shocks: Sufficient evidence demonstrates ICD has the ability to recognize and prevent malignant VAs by discharging high-energy shocks for defibrillation. Publication of landmark primary prevention ICD trials, the MADIT II [46] and SCD-HeFT [48] contributed to the widespread use of the ICD. However, post hoc analysis of these two trials raised concerns over adverse prognosis in patients receiving inappropriate ICD shocks [54]. Whether ICD shocks are markers of or indirectly contribute to ominous prognosis observed in patients receiving shocks remain unclear.

Mechanism of inappropriate ICD shock: Patients have described the experience of an ICD shock as an "earthquake", "being hit by a truck" or "being kicked by a mule" [55]. Given the traumatic nature of ICD shock, it would be ideal if the ICD could successfully distinguish VAs from non-lethal tachycardia and discharge appropriate shocks only for VT or VF [56]. However, in clinical practice, the software algorithms for ICD to discriminate VT/VF from non-lethal arrhythmias are not perfect and as many as 1 in 3 may receive inappropriate shocks described as discharge of shock for any other reason but VAs. Although the primary therapy of ICD is to detect VAs and deliver ATP or shocks to restore sinus rhythm, this benefit comes with increased risk of death for patients receiving shocks for non-lethal arrhythmias and any other reasons $[22,23]$.

A substantial proportion of ICD patients receive in appropriate shocks after implantation. The ALTITUDE survival study enrolling 194,000 patients reported inappropriate shocks in $17 \%$ of the patients [57], which represents a decline from 52\% reported in an earlier prospective cohort [58]. The expanded indications for prophylactic use of ICD (to include primary prevention) has resulted in the selection of patients who are less likely to experience life-threatening arrhythmias compared to the original indication only for secondary prevention population. Supraventricular tachycardia such as including sinus tachycardia, atrial fibrillation or flutter are the most common causes of inappropriate shocks $[21,22]$. They are able to meet the heart rate and duration criteria programmed in the ICD to deliver shocks and are responsible for greater than $90 \%$ of inappropriate detection leading to therapy [59]. Other causes include technical causes due to device failure including faulty components, oversensing of electrical noise or T-wave, lead fracture, electromagnetic interference, and double counting QRS complexes [22]. A post-hoc analysis of MADIT II trial, AF, tobacco use and diastolic hypertension increased the risk of inappropriate shocks [60].

\section{Preventive strategies}

The common clinical strategies used in the prevention of inappropriate ICD shocks include strategic ICD programming, pharmacologic support by AAD therapy and catheter ablation.

Strategic ICD programming: Strategic programming of ICD to use APT to detect and terminate VT is a safe and effective alternative to the use of shocks [24]. In ATP, the ICD discharges a burst of ventricularpaced beats at a faster rate than the underlying arrhythmias, which is able to terminate re-entrant arrhythmias and even monomorphic VTs as fast as $240 \mathrm{bpm}$, and in many cases of arrhythmias obviate the need for shocks. ATP has been shown to terminate $>90 \%$ of spontaneous VT [61]. The Pacing Fast Ventricular Tachycardia Reduces Shock Therapies (Pain FREE Rx II) trial [62] reported ICD programming strategy - ATP for VT $>200 / \mathrm{min}$ - reduced the need for ICD shock and improved the QoL but there was no difference in mortality. The Primary Prevention Parameters Evaluation (PREPARE) study [63] reported ATP, SVT discriminators and high-output first shock reduced the risk of any shock in the first year (8.5\% versus $16.9 \%$ ) with physician-programmed ICD parameters. These findings strongly indicate that ATP should be the preferred initial therapy for many monomorphic VT unless contraindicated. Although ICD are usually pre-programmed, it is important for the implanting physician to review the device setting to ensure they are appropriate for the individual patient $[23,24]$.

Pharmacologic support: Pharmacologic support with AAD may be useful in reducing the frequency of ICD shocks. These drugs suppress atrial and ventricular arrhythmias and slow down VT episodes, which allow patients to better tolerate VT hemodynamically, and thus, allow a broader use of ATP [60]. HF therapy with betablockers, angiotensin-converting enzyme - inhibitors and aldosterone receptor antagonists reduce the risk of HF hospitalization and mortality including SCD among patients with LV systole dysfunction [64-67]. Because these medications are underused in eligible ICD patients, they may add to the burden of ICD shocks. Optimal medical therapy may improve LV systolic function and obviate the need for ICD. Medical 
therapy also improve HF symptoms, mortality and the risk of VAs all together reducing the need for ICD therapy in implanted patients. Beta-blockers in particular may reduce ventricular rates in patients with supraventricular arrhythmias including AF and thus prevent inappropriate ICD shocks [60].

In a double blind trial comparing Sotalol to placebo enrolling 302 secondary prevention ICD patients, Sotalol was associated with $48 \%$ reduction in combined endpoint of all-cause mortality and first shock after one-year follow-up, with a greater reduction in inappropriate than appropriate shocks [68]. The Optimal Pharmacological Therapy in Implantable Cardioverter Defibrillator Patients (OPTIC) trial [69] randomized 412 ICD patients into beta-blocker and amiodarone, sotalol and beta-blocker. At one-year follow-up, amiodarone and betablocker had fewer shocks compared to sotalol (HR: 0.43) or beta-blocker alone (HR: 0.27). There was a trend towards fewer shocks with sotalol compared to beta-clocker alone (HR: $0.61 ; \mathrm{p}=0.055$ ). Amiodarone was associated with pulmonary and thyroid complications. There was no difference in mortality between the three treatment arms [69]. Whereas the addition of AAD reduces ICD shocks, there is need to individualize their addition because of risk of adverse effects of AAD.

Catheter ablation: Catheter ablation has emerged as an important adjunctive therapy for reducing shocks in ICD recipients [60]. Two large prospective randomized multicentre trials: The Substrate Mapping and Ablation in Sinus rhythm to Halt Ventricular Tachycardia (SMASHVT) trial [70] and Ventricular Tachycardia Ablation in Addition to Implantable Defibrillators in Coronary Heart Disease (VTACH) trial [71] have evaluated prophylactic VT ablation in ICD patients after documented VT/VF in the setting of ischaemic heart diseases. The SMASH-VT trial [70] evaluated catheter ablation and medical therapy in 128 post-MI patients and after tow-year follow-up catheter ablation reduced the need for ICD therapy (ATP or shocks) from 33\% to $12 \%$ (HR: 0.35 ) and appropriate shocks from $31 \%$ to $9 \%$ but mortality did not differ. The VTACH trial [71] enrolled 107 patients randomized to catheter ablation plus ICD and ICD alone. At two-year follow-up time to VT was longer in the ablation arm (18.6 versus 5.9 months) and freedom from VT was higher (HR: 0.61) but mortality did not differ. In a meta-analysis of five studies including SMASH-VT and VTACH and three observational studies, Mallidi et al. [72] associated catheter ablation with a $35 \%$ reduction in VT recurrence but with no effect on mortality.

\section{Psychosocial concerns}

Whereas the primary therapeutic target of the ICD to identify and terminate potentially life-threatening arrhythmias has received extensive research, there is relatively little research on ICD-related psychological and social outcomes. An early pioneering research only made a remote reference to psychological impact of ICD discharges terming them undesirable [73]. Even prior to the clinical use of the ICD, examination into responses to the pacemaker therapy provided valuable insight into the psychological effect of biomedical devices [7476]. However, these studies did not include the impact of lethal cardiac arrhythmias and the unique features of ICD shocks. A year after the US Food and Drug Administration (FDA) approved the ICD in 1985, Fricchione et al. [77] found irregular heart rhythms themselves are a major source of psychological difficulties.

Psychosocial outcomes: Typical psychological outcomes experienced by patients implanted with ICDs include anxiety, depression and worsening quality of life (QoL). Anxiety is the most common and problematic psychological outcomes affecting 13 to $38 \%$ of ICD patients [78-80]. Although anxiety constitutes an important variable for ICD recipients, discriminating between anxiety-related to ICD implantation and that related to shock remains a research objective $[81,82]$. Frequency of shocks and difficulties in psychological adjustment affect many ICD patients. The electric nature of ICD shock and the associated fear of death presents a possibility of post-traumatic stress disorder symptoms in ICD patients $[83,84]$. Depression occurs in 24 to $46 \%$ of ICD patients $[80,85]$, correlates with shock frequency [86] and may affect patient's mortality and cardiovascular symptoms by weakening the ability to cope and proper management of their disease [87]. Depression in ICD patients may lead to inadequate social support, deficit in physical functioning and a feeling of helplessness against shock $[88,89]$. Finally, the experience of receiving ICD or anticipating or requiring shock may depresses QoL. A recent meta-analysis confirms similar or slightly improved QoL in a large proportion of ICD patients [90]. However, majority of the studies found an association between shock and worsening QoL but clinically significant deficits occur after the experience of $>5$ device discharges [91].

Psychosocial interventions: Psychosocial outcomes in ICD patients potentially affect treatment efficacy leading to the need to develop appropriate therapies to improve patient outcomes. Initial interventions were simplistic, targeting patient education and social support using support groups. These methods however were unable to statistically demonstrate the therapeutic benefits despite reported qualitative gains [92,93]. The search for more significant effects led to the development of regimens that considered patient unique experience with medical devices involving specific education, telephone conversations and exercise that produced positive effects on psychosocial indices. Of these interventions, the ones including cognitive behavioural therapies targeting catastrophic cognition and avoidance behaviours associated with anticipated and experienced shock [94,95]. In a review of psychosocial intervention trials, Pedersen et al. [96] reported little impact on shocks and heart rate variability but a combination of cognitive-behavioural therapy and exercise training reduced depression symptoms and improved QoL. The Shock and Stress Management Program involving a combination of ICD-specific education, relaxation and stress management, cognitive-behavioural therapy and group discussion significantly reduced anxiety and increased patient acceptance of ICD technology [97].

Social acceptance and utility: Individual and societal acceptance of innovative medical technologies is critical for widespread utilization and the achievement of maximum benefits. Acceptance describes psychosocial accommodation and understanding of the device and its bio-psychosocial functioning [98]. Whereas individuals and the society are aware of the benefits of the ICD, full acceptance remains under-achieved as seen in under-utilization and patient's refusal of implantation despite ICD indication. Interaction between patient fears and concerns, physician communication, societal attitudes towards technology, and cultural biases undermine the full acceptance of ICD therapy [4].

Patient fears and concerns also arise from inadequate physicianpatient communication. The hurried state of today's healthcare system and low levels of patient literacy contributes to insufficient time and education about the indication for ICD to influence patient perception about ICD $[99,100]$. The fear of electric shock associated with worsening QoL, and perceived worsening cardiac function and catastrophic thoughts about death conspire to influence negatively device acceptance. The negative impact of ICD therapy on daily functioning such as driving and sexual activities, physical activities and 
changes in appearance may also influence device acceptance $[80,101$ 103]. Negative perception of device functioning and reliability shaped by increased media publicity of device recalls undermines patient's view of the device and confidence of the device providing adequate protection [104].

Patient's device acceptance occurs in the context of social and societal considerations suggesting the influence of society and social norms. However, research is lacking on evaluation of large-scale acceptance of device therapy in the U.S. despite the ICD market reaching maturity. Media attention on device reliability and functionality contributed to slowing market and sales but without concomitant decrease in the prevalence or risk of cardiac disease. However, cultural biases may stunt full societal acceptance of the ICD leading to disparities in implantation across cultures and gender. Despite comparable eligibility and indications for ICD across gender, men are 3.2 and 2.4 times more likely to receive ICD for primary and secondary-prevention cohorts [105]. Three other studies [106-108] supported gender bias in ICD implantation. Current evidence on psychosocial concerns in ICD therapy suggest the need for continued attention to patient factors and psychosocial functioning for ICD therapy to receive widespread individual and societal acceptance.

\section{Cost concerns}

Cost-effectiveness of ICD therapy: Affordability is an important influencing factor for the acceptance and use of medical devices. For ICD therapy, increased costs potentially limits its widespread use despite an increase in indications and subsequently needy patient populations. Several post-hoc analysis of large long-term follow-up clinical trials (MADIT I [44], MADIT II [46], SCD-HeFT [48], CIDS [43], AVID [13] have demonstrated substantial increase in cumulative medical costs among patients receiving ICD device [109-114]. Whether these added costs could prove to be a barrier of the potential for improved survival among ICD patients is still a subject of research [115]. Several randomized clinical trials have estimated both cost and clinical outcomes. The MADIT I [44] and MADIT II [46] trials report $54 \%$ and $32 \%$ reduction in overall mortality and cost-effectiveness ratio (higher than conventional AAD therapy) of $\$ 27,000$ and $\$ 39,200$ per life-year added respectively. The CIDS trial [33] found 20\% reduction and cost effectiveness ratio of $\$ 139,000$ per life-year added. The SCDHeFT trial [48] found 23\% reduction in mortality with increases in cost of $\$ 19,000$ over five years of follow-up in ICD patients compared to placebo. These variations in trials could have resulted from the different estimates of cost effectiveness of ICD in reducing mortality because all trials revealed similar increases in cost of care. After analysing the results using a common framework for a full gain in life expectancy and lifetime cost on each trial, cost effectiveness ranged between $\$ 25,300$ and $\$ 50,700$ per life added [116]. By contrast, the CABG-Patch [51] and DINAMIT [52] trials, ICD patients had lower survival and higher costs compared to patients randomized into conventional AAD therapy, indicating ICD therapy in these patients was not cost effective.

Strategies to improve cost effectiveness: The discussed evidence suggests that ICD therapy is not cost-effective for all types of patients indicated for implantation indicating a clear clinical need for careful selection of patients for ICD therapy to improve cost-effectiveness. ICD therapy seems to be more cost-effective for patients at an increased risk of arrhythmic death and low risk of other causes of death but there is insufficient evidence to confirm this statement [117]. Thus, there is a need to improve risk stratification to show clear results about costeffectiveness of ICD therapy in selected patients. Evidence is also lacking about the cost-effectiveness for the treatment with ICD in combination with AAD compared to AAD alone. The current gaps in knowledge on ICD cost-effectiveness suggests the need for additional risk stratification especially among patients with depressed LVEF to improve patient selection as well as to enhance cost-effectiveness [117]. Another promising and actionable approach to improve cost-effectives of ICD therapy is to lower the cost of the ICD device itself and improve device reliability and longevity.

\section{Conclusion}

Implantable cardioverter defibrillator (ICD) has evolved into a therapy with substantial life-saving benefits and multiple indications for the management of cardiac diseases. Its primary therapeutic aim is the protection against sudden cardiac death (SCD) due to sustained ventricular arrhythmias or indirectly life-threatening monomorphic ventricular tachycardia (VT). The ICD detects and terminates VT by anti-tachycardia pacing or electric shock and pacing in the case of bradycardia. It is indicated for secondary prevention of SCD in patients resuscitated from cardiac arrest and for primary prevention in patients at risk of a first time life-threatening ventricular arrhythmias or fibrillation. The most common indications by aetiology include patients with coronary artery disease, non-ischemic dilated cardiomyopathy, hypertrophic cardiomyopathy, arrhythmogenic RV dysplasia and genetic electrical disorders, accompanied by evidence of impaired LV systolic function. After indication, the selection for appropriate device is critical to achieve the greatest impact on procedural time and complexity, follow-up, patient outcomes and cost. Despite ICD therapy showing convincing evidence of significantly reduced mortality, widespread individual and societal acceptance and use of ICD needs continued attention paid to patient factors and psychosocial functioning. Pertinent factors such as appropriate patient selection, patient education, low device cost, and improved reliability and longevity would improve cost-effectiveness and subsequently increase patient acceptance and use of the ICD therapy.

\section{References}

1. Parkes J, Bryant J, Milne R (2002) Implantable cardioverter-defibrillators in arrhythmias: a rapid and systematic review of effectiveness. Heart 87: 438-442. [Crossref]

2. Mirowski M, Reid PR, Mower MM, Watkins L, Gott VL et al. (1980) Termination of malignant ventricular arrhythmias with an implanted automatic defibrillator in human beings. $N$ Engl J Med 303: 322-324. [Crossref]

3. Deyell MW, Tung S, Ignaszewski A (2010) The implantable cardioverter-defibrillator: from Mirowski to its current use. B C Med J 52: 248-253. [Crossref]

4. Matchett M, Sears SF, Hazelton G, Kirian K, Wilson E et al. (2009) The implantable cardioverter defibrillator: its history, current psychological impact and future. Expert Rev Med Devices 6: 43-50. [Crossref]

5. Tung R, Zimetbaum P, Josephson ME (2008) A critical appraisal of implantable cardioverter-defibrillator therapy for the prevention of sudden cardiac death. J Am Coll Cardiol 52: 1111-1121. [Crossref]

6. Kouwenhoven WB, Jude JR, Knickerbocker GG (1960) Closed-chest cardiac massage. Jama 173: 1064-1067. [Crossref]

7. Lown B, Fakhro AM, Hood WB, Thorn GW (1967). The coronary care unit: new perspectives and directions. Jama 199: 188-198. [Crossref]

8. Lee TH, Goldman L (1988) The coronary care unit turns 25: Historical trends and future directions. Ann Intern Med 108: 887-894. [Crossref]

9. Kastor JA (1989) Michel Mirowski and the automatic implantable defibrillator. Am J Cardiol 63: 977-982. [Crossref]

10. Kannel WB, Doyle JT, McNamara PM, Quickenton P, Gordon T (1975) Precursors of sudden coronary death. Factors related to the incidence of sudden death. Circulation 51: 606-613. [Crossref] 
11. Gillum RF (1989) Sudden coronary death in the United States: 1980-1985. Circulation 79: 756-765. [Crossref]

12. Lown B, Axelrod P (1972) Implanted standby defibrillators. Circulation 46: 637-639. [Crossref]

13. Defibrillators AV. Investigators (1997) A comparison of antiarrhythmic-drug therapy with implantable defibrillators in patients resuscitated from near-fatal ventricular arrhythmias. N Engl J Med 337: 1576-1583. [Crossref]

14. Epstein AE, DiMarco JP, Ellenbogen KA, Estes NM, Freedman RA et al. (2008) ACC/ AHA/HRS 2008 guidelines for device-based therapy of cardiac rhythm abnormalities: a report of the American College of Cardiology/American Heart Association Task Force on Practice Guidelines developed in collaboration with the American Association for Thoracic Surgery and Society of Thoracic Surgeons. J Am Coll Cardiol 51: e1-62. [Crossref]

15. Maisel WH, Moynahan M, Zuckerman BD, Gross TP, Tovar OH et al. (2006) Pacemaker and ICD generator malfunctions: analysis of Food and Drug Administration annual reports. Jama 295: 1901-1906. [Crossref]

16. Van Welsenes GH, Borleffs CJ, Van Rees JB, Atary JZ, Thijssen J et al. (2011) Improvements in 25 years of implantable cardioverter defibrillator therapy. Neth Heart $J$ 19: 24-30. [Crossref]

17. Swerdlow CD, Friedman PA (2005) Advanced ICD troubleshooting: part I. Pacing Clin Electrophysiol 28: 1322-1346. [Crossref]

18. Bardy GH, Troutman C, Poole JE, Kudenchuk PJ, Dolack GL et al. (1992) Clinica experience with a tiered-therapy, multi-programmable antiarrhythmia device. Circulation 85: 1689-1698. [Crossref]

19. Al-Khatib SM, Friedman P, Ellenbogen KA (2016) Defibrillators: selecting the right device for the right patient. Circulation 134: 1390-1404. [Crossref]

20. Zungsontiporn N, Loguidice M, Daniels J (2018) Important Parameters for Implantable Cardioverter Defibrillator Selection. Card Electrophysiol Clin 10: 145-152. [Crossref]

21. Braunschweig F, Boriani G, Bauer A, Hatala R, Herrmann-Lingen C et al. (2010) Management of patients receiving implantable cardiac defibrillator shocks: recommendations for acute and long-term patient management. Europace 12: 16731690. [Crossref]

22. Gehi AK, Mehta D, Gomes JA (2006) Evaluation and management of patients after implantable cardioverter-defibrillator shock. JAMA 296: 2839-2847. [Crossref]

23. Hauer RN, Aliot E, Block M, Capucci A, Lüderitz B et al. (2001) Study Group on Guidelines on ICDs of the Working Group on Arrhythmias and the Working Group on Cardiac Pacing of the European Society of Cardiology. Indications for implantable cardioverter defibrillator (ICD) therapy. Eur Heart $J$ 22: 1074-1081. [Crossref]

24. Tracy CM, Epstein AE, Darbar D, DiMarco JP, Dunbar SB et al. (2012) 2012 ACCF/ AHA/HRS focused update of the 2008 guidelines for device-based therapy of cardiac rhythm abnormalities: a report of the American College of Cardiology Foundation/ American Heart Association Task Force on Practice Guidelines. J Am Coll Cardiol 60: 1297-1313. [Crossref]

25. Jung W, Andresen D, Block M, Bocker D, Hohnloser SH et al. (2006) Leitlinien zur Implantation von Defibrillatoren. Clinical Research in Cardiology 95: 696-708. [Crossref]

26. Huikuri HV, Castellanos A, Myerburg RJ (2001) Sudden death due to cardiac arrhythmias. $N$ Engl J Med 345: 1473-1482. [Crossref]

27. Kastor JA (2002) Cardiac arrhythmias. [Crossref]

28. Rosman J, Hanon S, Shapiro M, Evans SJ, Schweitzer P (2006) Triggers of sustained monomorphic ventricular tachycardia differ among patients with varying etiologies of left ventricular dysfunction. Ann Noninvas Electro 11: 113-117. [Crossref]

29. Eckardt L, Breithardt G, Kirchhof P (2006) Approach to wide complex tachycardias in patients without structural heart disease. Heart 92: 704-711. [Crossref]

30. Shenthar J. Unusual incessant ventricular tachycardia: what is the underlying cause and the possible mechanism? Circulation: Arrhythmia and Electrophysiology 8: 15071511. [Crossref]

31. Lopez C, Oloriz T, Calvo N, Sancho I, Diaz F et al. (2017) Polymorphic ventricular arrhythmia triggered by temporary epicardial right ventricular stimulation after cardiac surgery. Heart Rhythm case reports 3: 571-573. [Crossref]

32. Bunch TJ, Hammill SC, White RD (2005) Outcomes after ventricular fibrillation outof-hospital cardiac arrest: expanding the chain of survival. Mayo Clinic Proceedings 80: 774-782. [Crossref]
33. Montalescot G, Sechtem U, Achenbach S, Andreotti F, Arden C et a;. (2013) 2013 ESC guidelines on the management of stable coronary artery disease: the Task Force on the management of stable coronary artery disease of the European Society of Cardiology. Eur Heart J 34: 2949-3003. [Crossref]

34. Zipes DP, Camm AJ, Borggrefe M, Buxton AE, Chaitman B et al. (2006) ACC/AHA ESC 2006 guidelines for management of patients with ventricular arrhythmias and the prevention of sudden cardiac death. J Am Coll Cardiol 48: e247-346. [Crossref]

35. Pinto YM, Elliott PM, Arbustini E, Adler Y, Anastasakis A et al. (2016) Proposal for a revised definition of dilated cardiomyopathy, hypokinetic non-dilated cardiomyopathy, and its implications for clinical practice: a position statement of the ESC working group on myocardial and pericardial diseases. Eur Heart J 37: 1850-1858. [Crossref]

36. Gersh BJ, Maron BJ, Bonow RO, Dearani JA, Fifer MA et al. (2011) 2011 ACCF/AHA guideline for the diagnosis and treatment of hypertrophic cardiomyopathy. Circulation 58: e212-e260. [Crossref]

37. Buxton AE, Lee KL, Fisher JD, Josephson ME, Prystowsky EN et al. (1999) A randomized study of the prevention of sudden death in patients with coronary artery disease. N Engl J Med 341: 1882-1890. [Crossref]

38. Hodgkinson KA, Parfrey PS, Bassett AS, Kupprion C, Drenckhahn J et al. (2005) The impact of implantable cardioverter-defibrillator therapy on survival in autosomaldominant arrhythmogenic right ventricular cardiomyopathy (ARVD5). J Am Coll Cardiol 45: 400-408. [Crossref]

39. Hermida JS, Lemoine JL, Aoun FB, Jarry G, Rey JL et al. (2000) Prevalence of the brugada syndrome in an apparently healthy population. AM J Cardiol 86: 91-94. [Crossref]

40. Sarkozy A, Boussy T, Kourgiannides G, Chierchia GB, Richter S et al. (2007) Longterm follow-up of primary prophylactic implantable cardioverter-defibrillator therapy in Brugada syndrome. Eur Heart 28: 334-344. [Crossref]

41. Jenni R, Oechslin E, Schneider J, Jost CA, Kaufmann PA (2001) Echocardiographic and pathoanatomical characteristics of isolated left ventricular non-compaction: a step towards classification as a distinct cardiomyopathy. Heart 86: 666-671. [Crossref]

42. Kuck KH, Cappato R, Siebels J, Ruppel R (2000) Randomized comparison of antiarrhythmic drug therapy with implantable defibrillators in patients resuscitated from cardiac arrest: the Cardiac Arrest Study Hamburg (CASH). Circulation 102: 748754. [Crossref]

43. Connolly SJ, Gent M, Roberts RS, Dorian P, Roy D et al. (2000) Canadian implantable defibrillator study (CIDS): a randomized trial of the implantable cardioverter defibrillator against amiodarone. Circulation 101: 1297-1302. [Crossref]

44. Moss AJ, Hall WJ, Cannom DS, Daubert JP, Higgins S et al. (1996) Improved survival with an implanted defibrillator in patients with coronary disease at high risk for ventricular arrhythmia. Multicenter Automatic Defibrillator Implantation Trial Investigators. N Engl J Med 335:1933-1940. [Crossref]

45. Buxton AE, Lee KL, Fisher JD, Josephson ME, Prystowsky EN et al. (1999) A randomized study of the prevention of sudden death in patients with coronary artery disease. Multicenter Unsustained Tachycardia Trial Investigators. N Engl J Med 341: 1882-1890. [Crossref]

46. Moss AJ, Zareba W, Hall WJ, Klein H, Wilber DJ et al. (2002) Prophylactic implantation of a defibrillator in patients with myocardial infarction and reduced ejection fraction. Multicenter Automatic Defibrillator Implantation Trial II Investigators. $N$ Engl J Med 346: 877-883. [Crossref]

47. Kadish A, Dyer A, Daubert JP, Quigg R, Estes NM et al. Defibrillators in Non-Ischemic Cardiomyopathy Treatment Evaluation (DEFINITE) Investigators (2004) Prophylactic defibrillator implantation in patients with nonischemic dilated cardiomyopathy. $N$ Engl J Med 350: 2151-2158. [Crossref]

48. Bardy GH, Lee KL, Mark DB, Poole JE, Packer DL et al. Sudden Cardiac Death in Heart Failure Trial (SCD-HeFT) Investigators (2005). Amiodarone or an implantable cardioverter-defibrillator for congestive heart failure. $N$ Engl J Med 352: 225-237. [Crossref]

49. Bänsch D, Antz M, Boczor S, Volkmer M, Tebbenjohanns J et al. (2002) Primary prevention of sudden cardiac death in idiopathic dilated cardiomyopathy: the Cardiomyopathy Trial (CAT). Circulation 105: 1453-1458. [Crossref]

50. Strickberger SA, Hummel JD, Bartlett TG, Frumin HI, Schuger CD et al. AMIOVIRT Investigators. (2003), Amiodarone versus implantable cardioverter-defibrillator: randomized trial in patients with non-ischemic dilated cardiomyopathy and asymptomatic non-sustained ventricular tachycardia: AMIOVIRT. J Am Coll Cardiol 41: 1707-1712. [Crossref] 
51. Bigger Jr JT (1997) Prophylactic use of implanted cardiac defibrillators in patients at high risk for ventricular arrhythmias after coronary-artery bypass graft surgery. Coronary Artery Bypass Graft (CABG) Patch Trial Investigators. $N$ Engl J Med 337: 1569-1575. [Crossref]

52. Dorian P, Hohnloser SH, Thorpe KE, Roberts RS, Kuck KH et al. (2010) Mechanisms underlying the lack of effect of implantable cardioverter-defibrillator therapy on mortality in high-risk patients with recent myocardial infarction: insights from the Defibrillation in Acute Myocardial Infarction Trial (DINAMIT). Circulation 122: 2645-2652. [Crossref]

53. Veenhuyzen GD, Singh SN, McAreavey D, Shelton BJ, Exner DV (2001) Prior coronary artery bypass surgery and risk of death among patients with ischemic left ventricular dysfunction. Circulation 104: 1489-1493. [Crossref]

54. Li A, Kaura A, Sunderland N, Dhillon PS, Scott PA (2016). The significance of shocks in implantable cardioverter defibrillator recipients. Arrhythm Electrophysiol Rev 5: 110-116. [Crossref]

55. Ahmad M, Bloomstein L, Roelke M, Bernstein AD, Parsonnet V. Patients' attitudes toward implanted defibrillator shocks. Pacing Clin Electrophysiol 23: 934-938. [Crossref]

56. Mishkin JD, Saxonhouse SJ, Woo GW, Burkart TA, Miles WM et al. (2009) Appropriate evaluation and treatment of heart failure patients after implantable cardioverterdefibrillator discharge: time to go beyond the initial shock. J Am Coll Cardiol 54: $1993-$ 2000. [Crossref]

57. Saxon LA, Hayes DL, Gilliam FR, Heidenreich PA, Day J et al. (2010) Long-term outcome after ICD and CRT implantation and influence of remote device follow-up: the ALTITUDE survival study. Circulation 122: 2359-2367. [Crossref]

58. Koller MT, Schaer B, Wolbers M, Sticherling C, Bucher HC et al. (2008) Death without prior appropriate implantable cardioverter-defibrillator therapy: a competing risk study. Circulation 117: 1918-1926. [Crossref]

59. Wilkoff BL, Hess M, Young J, Abraham WT (2004) Differences in tachyarrhythmia detection and implantable cardioverter defibrillator therapy by primary or secondary prevention indication in cardiac resynchronization therapy patients. $J$ Cardiovasc Electrophysiol 15: 1002-1009. [Crossref]

60. Borne RT, Varosy PD, Masoudi FA (2013). Implantable cardioverter-defibrillator shocks: epidemiology, outcomes, and therapeutic approaches. JAMA Internal Medicine 173:859-865 [Crossref]

61. Nasir NN, Pacifico PA, Doyle DT, Earle EN, Hardage HM et al. (1997) Spontaneous ventricular tachycardia treated by anti-tachycardia pacing. Am J Cardiol 79: 820-822. [Crossref]

62. Wathen MS, DeGroot PJ, Sweeney MO, Stark AJ, Otterness MF et al. (2004) Prospective randomized multicentre trial of empirical anti-tachycardia pacing versus shocks for spontaneous rapid ventricular tachycardia in patients with implantable cardioverterdefibrillators: Pacing Fast Ventricular Tachycardia Reduces Shock Therapies (Pain FREE Rx II) trial results. Circulation 110: 2591-2596. [Crossref]

63. Wilkoff BL, Williamson BD, Stern RS, Moore SL, Lu F et al. (2008) Strategic programming of detection and therapy parameters in implantable cardioverterdefibrillators reduces shocks in primary prevention patients: results from the PREPARE (Primary Prevention Parameters Evaluation) study. J Am Coll Cardiol 52: 541-550. [Crossref]

64. Hjalmarson A, Goldstein S, Fagerberg B, Wedel H, Waagstein F et al. (2000) Effects of controlled-release metoprolol on total mortality, hospitalizations, and well-being in patients with heart failure: the Metoprolol CR/XL Randomized Intervention Trial in congestive heart failure (MERIT-HF). Jama 283: 1295-1302. [Crossref]

65. Packer M, Fowler MB, Roecker EB, Coats AJ, Katus HA et al. (2002) Effect of carvedilol on the morbidity of patients with severe chronic heart failure: results of the carvedilol prospective randomized cumulative survival (COPERNICUS) study. Circulation 106: 2194-2199. [Crossref]

66. Flather MD, Yusuf S, Køber L, Pfeffer M, Hall A et al. (2000) Long-term ACE-inhibitor therapy in patients with heart failure or left-ventricular dysfunction: a systematic overview of data from individual patients. The Lancet 355: 1575-1581. [Crossref]

67. Bapoje SR, Bahia A, Hokanson JE, Peterson PN, Heidenreich PA et al. (2013) The Effects of Mineralocorticoid Receptor Antagonists on the Risk of Sudden Cardiac Death in Patients with Left Ventricular Systolic Dysfunction: A Meta-analysis of Randomized Controlled Trials. Circulation: Heart Fail 6: 166-173. [Crossref]

68. Pacifico A, Hohnloser SH, Williams JH, Tao B, Saksena S et al. (1999) Prevention of implantable-defibrillator shocks by treatment with sotalol. $N$ Engl J Med 340: 18551862. [Crossref]
69. Connolly SJ, Dorian P, Roberts RS, Gent M, Bailin S et al. (2006) Comparison of $\beta$-blockers, amiodarone plus $\beta$-blockers, or sotalol for prevention of shocks from implantable cardioverter defibrillators: the OPTIC study: a randomized trial. Jama 295: 165-1671. [Crossref]

70. Reddy VY, Reynolds MR, Neuzil P, Richardson AW, Taborsky M (2007) Prophylactic catheter ablation for the prevention of defibrillator therapy. N Engl J Med 357: 26572665. [Crossref]

71. Kuck KH, Schaumann A, Eckardt L, Willems S, Ventura R et al. (2010) Catheter ablation of stable ventricular tachycardia before defibrillator implantation in patients with coronary heart disease (VTACH): a multicentre randomised controlled trial. The Lancet 375: 31-40. [Crossref]

72. Mallidi J, Nadkarni GN, Berger RD, Calkins H, Nazarian S (2011) Meta-analysis of catheter ablation as an adjunct to medical therapy for treatment of ventricular tachycardia in patients with structural heart disease. Heart rhythm 8: 503-510. [Crossref]

73. Mirowski M (1985) The automatic implantable cardioverter-defibrillator: an overview. $J$ Am Coll Cardiol 6: 461-466. [Crossref]

74. Crisp AH, Stonehill E (1969) Aspects of the psychological status of patients treated with cardiac pacemakers. Postgrad Med J 45: 423-427. [Crossref]

75. Dlin BM, Fischer HK, Huddell B (1968) Psychologic adaptation to pacemaker and open-heart surgery. Arch Gen Psychiatry 19: 599-610. [Crossref]

76. Dlin BM, Winters W, Fischer HK, Koch P (1966) Psychological adaptation to pacemaker following cardiac arrest. Psychosomatics 7: 73-80. [Crossref]

77. Fricchione GL, Vlay SC (1986) Psychiatric aspects of patients with malignant ventricular arrhythmias. Am J Psychiatry 143: 1518-1526. [Crossref]

78. Wallace RL, Sears Jr SF, Lewis TS, Griffis JT, Curtis A et al. (2002) Predictors of quality of life in long-term recipients of implantable cardioverter defibrillators. $J$ Cardiopulm Rehabil Prev 22: 278-281. [Crossref]

79. Burke J, Hallas CN, Clark-Carter D, White D, Connelly D (2003) The psychosocial impact of the implantable cardioverter defibrillator: A meta-analytic review. $B r J$ Health Psychol 8: 165-178. [Crossref]

80. Sears Jr SF, Conti JB, Curtis AB, Saia TL, Foote R et al. (1999) Affective distres and implantable cardioverter defibrillators: cases for psychological and behavioural interventions. Pacing Clin Electrophysiol 22: 1831-1834. [Crossref]

81. Vlay SC, Olson LC, Fricchione GL, Friedman R (1989) Anxiety and anger in patients with ventricular tachyarrhythmias. Responses after automatic internal cardioverter defibrillator implantation. Pacing Clin Electrophysiol 12: 366-373. [Crossref]

82. Lemon J, Edelman S (2007) Psychological adaptation to ICDs and the influence of anxiety sensitivity. Psychol Health Med 12: 163-1671. [Crossref]

83. Neel M (2000) Posttraumatic stress symptomatology in patients with automatic implantable cardioverter defibrillators: nature and intervention. Int J Emerg Ment Health 2: 259-263. [Crossref]

84. Hamner M, Hunt N, Gee J, Garrell R, Monroe R (1999) PTSD and automatic implantable cardioverter defibrillators. Psychosomatics 40: 82-85. [Crossref]

85. Bilge AK, Ozben B, Demircan S, Cinar M, Yilmaz E et al. (2006) Depression and anxiety status of patients with implantable cardioverter defibrillator and precipitating factors. Pacing Clin Electrophysiol 29: 619-626. [Crossref]

86. Whang W, Albert CM, Sears SF, Lampert R, Conti JB et al. (2005) Depression as a predictor for appropriate shocks among patients with implantable cardioverterdefibrillators: results from the Triggers of Ventricular Arrhythmias (TOVA) study. $J$ Am Coll Cardiol 45: 1090-1095. [Crossref]

87. Carney RM, Freedland KE (2003) Depression, mortality, and medical morbidity in patients with coronary heart disease. Biol psychiatry 54: 241-247. [Crossref]

88. Luyster FS, Hughes JW, Waechter D, Josephson R. Resource loss predicts depression and anxiety among patients treated with an implantable cardioverter defibrillator. Psychosom Med 68: 794-800. [Crossref]

89. Goodman M, Hess B (1999) Could implantable cardioverter defibrillators provide a human model supporting the learned helplessness theory of depression? Gen Hosp Psychiatry 21: 382-385. [Crossref]

90. Francis J, Johnson B, Niehaus M (2006) Quality of life in patients with implantable cardioverter defibrillators. Indian Pacing Electrophysiol J 6: 173-181. [Crossref]

91. Passman R, Subacius H, Ruo B, Schaechter A, Howard A et al. (2007) Implantable cardioverter defibrillators and quality of life: results from the defibrillators in nonischemic cardiomyopathy treatment evaluation study. Arch Intern Med 167: 22262232. [Crossref] 
92. Badger JM, Morris PL (1989) Observations of a support group for automatic implantable cardioverter-defibrillator recipients and their spouses. Heart \& lung: the journal of Critical Care 18: 238-243. [Crossref]

93. Molchany CA, Peterson KA (1994) The psychosocial effects of support group intervention on AICD recipients and their significant others. Prog Cardiovasc Nurs 9: 23-29. [Crossref]

94. Chevalier P, Cottraux J, Mollard E, Sai N, Brun S, Burri H et al. (2006) Prevention of implantable defibrillator shocks by cognitive behavioral therapy: a pilot trial. Am Heart $J$ 151: 191-e1. [Crossref]

95. Irvine J, Firestone J, Ong L, Cribbie R, Dorian P et al. (2011) A randomized controlled trial of cognitive behavior therapy tailored to psychological adaptation to an implantable cardioverter defibrillator. Psychosomatic Medicine 73: 226-233. [Crossref]

96. Pedersen SS, Van Den Broek KC, Sears Jr SF (2007) Psychological intervention following implantation of an implantable defibrillator: a review and future recommendations. Pacing Clin Electrophysiol 30: 1546-1554. [Crossref]

97. Sears SF, Sowell LD, Kuhl EA, Kovacs AH, Serber ER et al. (2007) The ICD shock and stress management program: a randomized trial of psychosocial treatment to optimize quality of life in ICD patients. Pacing Clin Electrophysiol 30: 858-864. [Crossref]

98. Burns JL, Serber ER, Keim S, Sears SF (2005) Measuring patient acceptance of implantable cardiac device therapy: initial psychometric investigation of the Florida Patient Acceptance Survey. J Cardiovasc Electrophysiol 16: 384-390. [Crossref]

99. Agard A, Lofmark R, Edvardsson N, Ekman I (2007) Views of patients with heart failure about their role in the decision to start implantable cardioverter-defibrillator treatment: prescription rather than participation. J Med Ethics 33: 514-518. [Crossref]

100. Carroll SL, Strachan PH, de Laat S, Schwartz L, Arthur HM (2013) Patients' decision making to accept or decline an implantable cardioverter defibrillator for primary prevention of sudden cardiac death. Health Expectations 16: 69-79. [Crossref]

101. Shiyovich A, Ben IZ, Plakht Y, Amit G, Grosbard A et al. (2007) Sexual dysfunction, depression and quality of life in male implantable cardioverter defibrillator (ICD) recipients--with and without shock delivery. Harefuah 146: 594-598. [Crossref]

102. Shea JB (2004) Quality of Life Issues in Patients With Implantable Cardioverter Defibrillators Driving, Occupation, and Recreation. AACN Advanced Critical Care 15: 478-489. [Crossref]

103. Lemon J, Edelman S, Kirkness A (2004) Avoidance behaviors in patients with implantable cardioverter defibrillators. Heart \& Lung: The Journal of Acute and Critical Care 33: 176-182. [Crossref]

104. Sears Jr SF, Conti JB (2006) Psychological aspects of cardiac devices and recalls in patients with implantable cardioverter defibrillators. Am J Cardiol 98: 565-567. [Crossref]

105. Curtis LH, Al-Khatib SM, Shea AM, Hammill BG, Hernandez AF et al. (2007) Sex differences in the use of implantable cardioverter-defibrillators for primary and secondary prevention of sudden cardiac death. Jama 298: 1517-1524. [Crossref]
106. Lin G, Meverden RA, Hodge DO, Uslan DZ, Hayes DL et al. (2008) Age and gender trends in implantable cardioverter defibrillator utilization: a population based study. $J$ Interv Card Electrophysiol 22: 65-70. [Crossref]

107. Davis DR, Tang AS, Lemery R, Green MS, Gollob MH et al. (2006) Influence of gender on ICD implantation for primary and secondary prevention of sudden cardiac death. Europace 8: 1054-1056. [Crossref]

108. Gauri AJ, Davis A, Hong T, Burke MC, Knight BP. Disparities in the use of primary prevention and defibrillator therapy among blacks and women. Am J Med 119: 167-e17-e21. [Crossref]

109. Zwanziger J, Hall WJ, Dick AW, Zhao H, Mushlin AI et al. (2006) The cost effectiveness of implantable cardioverter-defibrillators: results from the Multicentre Automatic Defibrillator Implantation Trial (MADIT)-II. $J$ Am Coll Cardiol 47(11):2310-2318. [Crossref]

110. Mark DB, Nelson CL, Anstrom KJ, Al-Khatib SM, Tsiatis AA et al. (2006) Costeffectiveness of defibrillator therapy or amiodarone in chronic stable heart failure: results from the Sudden Cardiac Death in Heart Failure Trial (SCD-HeFT). Circulation 114: 135-142. [Crossref]

111. Mushlin AI, Hall WJ, Zwanziger J, Gajary E, Andrews M et al. (1998) The Costeffectiveness of Automatic Implantable Cardiac Defibrillators:: Results From MADIT. Circulation 97: 2129-2135. [Crossref]

112. Weiss JP, Saynina O, McDonald KM, McClellan MB, Hlatky MA (2002) Effectiveness and cost-effectiveness of implantable cardioverter defibrillators in the treatment of ventricular arrhythmias among Medicare beneficiaries. Am J Med 112 519-527. [Crossref]

113. O'brien BJ, Connolly SJ, Goeree R, Blackhouse G, Willan A et al. (2001) Costeffectiveness of the implantable cardioverter-defibrillator: results from the Canadian Implantable Defibrillator Study (CIDS). Circulation 103: 1416-1421. [Crossref]

114. Larsen G, Hallstrom A, McAnulty J, Pinski S, Olarte A et al. (2002) Cost-effectiveness of the implantable cardioverter-defibrillator versus antiarrhythmic drugs in survivors of serious ventricular tachyarrhythmias: results of the Antiarrhythmics Versus Implantable Defibrillators (AVID) economic analysis substudy. Circulation 105: 2049-2057. [Crossref]

115. Hlatky MA, Sanders GD, Owens DK (2005) Evidence-based medicine and policy: the case of the implantable cardioverter defibrillator. Health Affairs 24: 42-51. [Crossref]

116. Sanders GD, Hlatky MA, Owens DK (2005) Cost-effectiveness of implantable cardioverter-defibrillators. $N$ Engl J Med 353: 1471-1480. [Crossref]

117. Owens DK, Sanders GD, Heidenreich PA, McDonald KM, Hlatky MA (2002) Effect of risk stratification on cost-effectiveness of the implantable cardioverter defibrillator. Am Heart J 144: 440-448. [Crossref]

Copyright: (C2019 Albakri A. This is an open-access article distributed under the terms of the Creative Commons Attribution License, which permits unrestricted use, distribution, and reproduction in any medium, provided the original author and source are credited. 